\title{
Correlation of Population Factors, Compliance With Masking and Social Distance, Vaccination and Covid-19 Infection in Central Appalachia: A Cross- Sectional Study
}

\section{J. Suzanne Moore}

East Tennessee State University James H Quillen College of Medicine https://orcid.org/0000-00034230-8698

Hibah Virk

East Tennessee State University James H Quillen College of Medicine https://orcid.org/0000-00021354-423X

\section{Jeffrey A Summers ( $\nabla$ summersj@etsu.edu )}

East Tennessee State University James H Quillen College of Medicine https://orcid.org/0000-00015909-0299

\section{Research}

Keywords: Compliance, SARS-Cov-2, survey, immunocompromise

Posted Date: November 2nd, 2021

DOI: https://doi.org/10.21203/rs.3.rs-957609/v1

License: (c) (i) This work is licensed under a Creative Commons Attribution 4.0 International License. Read Full License 


\section{Abstract}

\section{Background}

Compliance with guidelines, including the use of masks and social distancing and vaccinations has been poor. Our study examined what factors may identify those who will be more or less compliant especially with regards to those with identified higher risk.

\section{Methods}

A telephone survey of 200 adult patients from two practices, one General Internal Medicine and the other Rheumatology, was performed in May and June of 2021. Questions included age, sex, perception of immunocompetence, smoking history, mask and social distancing compliance, Covid-19 symptoms and/or test proven infection, and immunization status for Covid-19. Those agreeing to participate also had a chart review for body mass index (BMI), physician assessed immunocompetence, and diabetes.

\section{Results}

No clinical factors approached statistical significance for prediction of compliance or non-compliance. However, compliance with mask and social distancing highly correlated with vaccination and avoidance of infection.

\section{Conclusion}

Attempts to improve compliance cannot be focused on any of the particular groups examined in this study.

\section{Background}

The recommended responses to the current Covid-19 pandemic are not always followed. In our east Tennessee/mid Appalachia region we have seen significant resistance to wearing masks, social distancing, and more recently with vaccination. As of this writing, only $37 \%$ of those eligible for the vaccination have received it here [1].

Our study endeavored to define what factors impact patient compliance. Our first question was whether or not patients who are immunocompromised would be more compliant. A related question was whether immunocompromised patients realize they are immunocompromised. We then looked at a number of other factors. For example, we expected that smokers would be less likely to be compliant.

Finally, we assessed whether patients compliant with masks and social distancing were then more likely to be vaccinated, and whether noncompliant patients were more likely to have had symptomatic Covid-19 infections. 


\section{Methods}

We performed a telephone survey on a randomized selection of 200 patients in our academic general internal medicine and rheumatology practices. After obtaining informed consent, the patient was asked a series of questions relating to Covid-19 symptoms, proven infection, and compliance with mask wearing and social distancing. They were also asked whether they had received the covid vaccine and if not, whether they intended vaccination in the future. They were also asked whether they were immunocompromised, their smoking history, age and sex. We then did a chart review to obtain most recent $\mathrm{BMI}$, whether they were immunocompromised by physician assessment, and presence of diabetes.

The results of the survey were then analyzed for any clinical characteristic or combination of characteristics that correlated with compliance defined as mask wearing in public and social distancing recommendations. A deep neural network was created to evaluate whether the combination of the factors would uncover a pattern that would be predictive of compliance. Finally, we analyzed whether compliance with masks and social distancing was predictive of compliance with vaccination recommendations and with having symptoms of and/or proven infection with the SARS-CoV-2 virus.

\section{Results}

Our population characteristics are shown in Table 1. Initial analysis of a number of factors (age, sex, body mass index, diabetes, perceived immunocompromise, physician assessment of immunocompromise, current smoker, former smoker) showed none were predictive of the composite of mask and distancing compliance (Table 2). Combining all factors was only $62.5 \%$ accurate in predicting compliance, again not statistically significant. However, not complying was correlated with both getting proven Covid-19 or having probable Covid-19 (combined positive test, having had typical symptoms, or anosmia) ( $p<0.031, p<0.025$ respectively). 
Table 1

Population features

\begin{tabular}{|ll|}
\hline Factor (and range where applicable) \\
\hline Age & $59.7(18-86)$ \\
\hline BMI & $33.1(18.4-66.8)$ \\
\hline Perceived immunocompromise & $39.50 \%$ \\
\hline Physician opinion of immunocompromise & $41.50 \%$ \\
\hline Diabetes & $19.50 \%$ \\
\hline Smoker & $18 \%$ \\
\hline Current or Former Smoker & $46.50 \%$ \\
\hline Female Sex & $73.50 \%$ \\
\hline Age in years, BMI = Body Mass Index & \\
\hline
\end{tabular}

Table 2

Comparisons

\begin{tabular}{|llll|}
\hline & $\begin{array}{l}\text { Mask/Distance } \\
\text { compliance }\end{array}$ & $\begin{array}{l}\text { Mask/Distance } \\
\text { compliance }\end{array}$ & \\
\hline Factor & With Factor, Percent & Without Factor, Percent & P Value \\
\hline Perceived Compromise & 65.8 & 60.3 & 0.5 \\
\hline $\begin{array}{l}\text { Physician opinion } \\
\text { Compromised }\end{array}$ & 65.1 & 60.7 & 0.63 \\
\hline Current Smokers & 66.7 & 61.6 & 0.7 \\
\hline Current or Former Smokers & 61.3 & 63.6 & 0.855 \\
\hline Sex (Female) & 61.9 & 64.2 & 0.9 \\
\hline Diabetes & 69.2 & 60.9 & 0.43 \\
\hline Covid tested Positive & 45.2 & 65.9 & 0.049 \\
\hline Covid Composite & 47.9 & 68.2 & 0.036 \\
\hline $\begin{array}{l}\text { Vaccine Composite } \\
\text { Covid Composite is any of positive test, appropriate symptoms, anosmia. Vaccine Composite is }\end{array}$ \\
\hline
\end{tabular}


Similarly, compliance with mask and distancing strongly correlated with vaccination. Of the compliant patients, $72 \%$ were either vaccinated or intending vaccination compared with $29 \%$ of those who were not compliant $(p<0.000004$, correlation coefficient $0.374, p<0.00000005)$.

\section{Discussion}

As of August 27, 2021, the CDC (Centers for Disease Control) reported 52\% of the total United States population has been fully vaccinated against COVID-19. Our home state of Tennesssee was only $41.3 \%$ fully vaccinated with even lower numbers in our region. [1] [2] Vaccine hesitancy even before the pandemic has been reported to be higher in the U.S. than in low-income countries [3]. Thus, the role of predictive models for social distancing/masking and vaccine behaviors is essential in ending the COVID19 pandemic.

Our survey of 200 patients from the Appalachian Highlands region sought to prove immunocompromised patients in our academic practice would social distance and mask more than the general internal medicine patients surveyed, though this assumption was disproved. Of the factors we examined, we found that patients who were either COVID positive, had COVID related symptoms or anosmia were less likely to be vaccinated or practice social distancing/masking.

A common thread of reviewed studies was an effort to build a model for predicting compliance with mask and distancing behaviors $[4,5,6]$. Though our study may have been limited by small sample size, regional bias, and including our patients of record, the larger, anonymous surveys reviewed did not produce a consensus on demographic factors to predict social distancing or compliance. Addressing general vaccine hesitancy may lead to a cost effective and generalizable public health model to increase compliance with the COVID-19 vaccine and preventable illness.

\section{Conclusions}

Our study sought to identify clinical characteristics that would point to better compliance with recommendations in the Covid-19 pandemic. As no such clinical characteristics were identified, attempts to influence public behavior cannot be directed to subgroups, rather much be directed at the population as a whole. Also notable is that those who were compliant with some items (mask wearing and social distancing) were also more likely to be compliant in other areas (vaccination) and also more likely not to become ill with Covid-19.

\section{Abbreviations}

BMI: Body Mass Index

CDC: Centers for Disease Control

ETSU: East Tennessee State University 
HIPAA: Health Insurance Portability and Accountability Act

IRB: Institutional Review Board

Min: minimum

Max: maximum

PHI: Protected Health Information

Pop: population

Std Dev: Standard Deviation

\section{Declarations}

\section{Ethics approval and consent to participate}

This project was approved by the ETSU (East Tennessee State University) Institutional Review Board (IRB)

Each participant verbally consented to the IRB approved consent form

\section{Consent for Publication}

Each participant verballed consented to publication via the IRB approved consent form

\section{Availability of data and materials}

Data is in a HIPAA (Health Insurance Portability and Accountability Act) compliant repository at East Tennessee State University Department of Internal Medicine. This contains PHI (protected health information) according to HIPAA rules and is not to be released without approval from the compliance office at the university

\section{Competing interests}

None (Not Applicable)

\section{Funding}

Student received a research stipend through the ETSU Quillen College of Medicine

\section{Authors' Contributions}

a. JM contributed to study design, navigating the IRB, on site availability during the survey section to answer questions, writing the Background and Discussion sections

b. HV contributed to study design, study performance, writing the Background and Discussion sections 
c. JS contributed to study design, data analysis, neural network design and implementation, writing the Abstract, Methods, Results, and Conclusions

\section{Acknowledgements}

None (Not Applicable)

\section{References}

1. BalladHealth Scorecard https://www.balladhealth.org/sites/balladhealth/files/COVID_19_Scorecard_Aug_25_2021.pdf last accessed September 13, 2021

2. Centers For Disease Control. CDC Covid Data Tracker https://covid.cdc.gov/covid-datatracker/\#datatracker-home (accessed September 12021 ).

3. Machingaidze, S. \& Wiysonge,C.S. Understanding COVID-19 vaccine hesitancy. Nature Medicine 27,1338-1344 (2021).

4. Shmueli, L. Predicting intention to receive COVID-19 vaccine among the general population using the health belief model and the theory of planned behavior model. BMC Public Health 21, 804 (2021).

5. Pedersen, M. \& Favero, N. Social distancing during the COVID-19 Pandemic: Who are the present and future noncompliers? Public Administration Review 80, 805-814 (2020).

6. Fazio,R.,Ruisch,B.,Moore,C., Granados,J. Who is (not) complying with the U.S. social distancing direction and why? Testing a general framework of compliance with virtual measure of social distancing. PLoS ONE 16(2):e0247520 